\title{
Synthesis of magnetic nanoparticles by microwave for aplication in lubricantion
}

\author{
Ana Emília Diniz Silva Guedes ${ }^{1}$, Aline Raquel Vieira Silva ${ }^{2}, V_{\text {aldicleide Silva e Mello }}^{3}$, Felipe da Silva \\ Pontes4, Salete Martins Alves ${ }^{5}$, Tirso Lorenzo Reyes Carvajal ${ }^{6}$ \\ ${ }^{1}$ Federal University of Rio Grande do Norte, Natal/RN - Brazil (aedsguedes@ gmail.com) \\ ${ }^{2}$ Federal University of Rio de Janeiro, Rio de Janeiro/RJ- Brazil(alinemateriais@ hotmail.com). \\ 3,4,5Federal University of Rio Grande do Norte, Natal/RN - Brazil (valdkqi@ hotmail.com; felipe_silva707@ hotmail.com; \\ saletealves@ect.ufrn.br ). \\ ${ }^{6}$ Dr., Instituto de Tecnologia e Educação Galileo da Amazônia (ITEGAM)-Manaus/AM-Brasil(tirsolrca@ gmail.com).
}

\begin{abstract}
The synthesis and characterization of magnetic nanoparticles have been widely studied due to their applications in several areas of knowledge. Obtaining nanomaterials as additives with specific properties for industrial lubricating oil has been getting many expectations that can minimize tribological problems, in addition the friction and wear handle failures in equipment and machinery. For iron oxide nanoparticles, the most important variations are caused by the observed phenomena that are intrinsic or become dominant in nano-scale. These phenomena include confinement due to the size, predominance interface phenomena and quantum phenomena. However, the study of these magnetic phenomena of nanoparticles is connected with type and morphology, directly influenced by the synthesis. Therefore the aim of this study is to synthesize the nanoparticles by microwave power $300 \mathrm{~W}$, in two different times and temperatures, 0.5 minutes and 2.0 minutes, $55^{\circ} \mathrm{C}$ and $95{ }^{\circ} \mathrm{C}$, respectively, obtaining them with different physical and chemical properties, also be characterized by X-Ray Diffraction and correlated with crystallite size, time, kinetic energy study nucleation and about how the magnetic nanoparticles can act as antiwear additives.
\end{abstract}

Keywords: Magneticnanoparticles, X-Ray Diffraction, microwave synthesis

\section{Síntesis de nanopartículas magnéticas por microondas para la aplicación en la lubricación}

\begin{abstract}
RESUMEN
La síntesis y caracterización de nanopartículas magnéticas han sido ampliamente estudiadas debido a sus aplicaciones en diversas áreas del conocimiento. La obtención de nanomateriales como aditivos con propiedades específicas para el aceite de lubricación industrial ha estado recibiendo muchas expectativas que pueden minimizar los problemas tribológicos, además de la fricción y el desgaste manejar fallos en los equipos y maquinaria. Para las nanopartículas de óxido de hierro, las variaciones más importantes son causadas por los fenómenos observados que son intrínsecos o ser dominante en nano-escala. Estos fenómenos incluyen el confinamiento debido al tamaño, los fenómenos de interfaz de predominio y los fenómenos cuánticos. Sin embargo, el estudio de estos fenómenos magnéticos de las nanopartículas está conectado con el tipo y la morfología, la influencia directa de la síntesis. Por tanto, el objetivo de este trabajo es sintetizar las nanopartículas de $300 \mathrm{~W}$ de potencia de microondas, en dos momentos diferentes y temperaturas, 0,5 minutos y 2,0 minutos, $55^{\circ} \mathrm{C}$ y $95^{\circ} \mathrm{C}$, respectivamente, obteniéndose con diferentes propiedades físicas y químicas, también será caracterizado por difracción de rayos $\mathrm{X}$ y se correlacionó con tamaño de los cristalitos, tiempo, cinética de nucleación estudio de energía y de cómo las nanopartículas magnéticas pueden actuar como aditivos antidesgaste.
\end{abstract}

Palabras clave: Magneticnanoparticles, difracción de rayos X, la síntesis de micro-ondas.

\section{INTRODUCTION}

There are many methods for the preparation of ferrites, with the spinel structure form, including solid state reaction, co- precipitation method, hydrothermal method, micro-emulsion method, sol-gel method [1]. Some researchers have been studied synthesis of ferrites nanoparticles, but these methods require heat treatment to get better crystalline structure and need along time to 
process. Thus, the introduction of microwave process seemed asgood method to obtain nanoparticles, because it reduces process time and energy cost. The process assisted by Microwave is often used to be rapid and has the potential to enhance the crystallization kinetics of reaction process. For microwave heating, the high polarizability of the solvent makes it an excellent microwaveabsorbing agent, thus leading to a high heating rate and a significantly shorten reaction time [2].

Iron oxides, including magnetite and hematite, have been studied due to their interesting properties, as superparamagnetic properties. In this paper, ferrites nanoparticles were obtained through $\mathrm{FeCl} 3.6 \mathrm{H}_{2} \mathrm{O}$. The formation of nanoparticles depends on the time, heating, power, controlled by microwave process. The crystal structure of ferrites were determined by X-Ray Diffraction and observed the difference between samples.

\section{I.1 NANOFLUIDS}

Nanotechnology is being used in many application targeted to provide cleaner, more efficient energy supplies and uses. The advent of high heat flow processes has created significant demand for new technologies. A nanofluid can also be used for increasing the dielectric strength and life of the transformer oil by dispersing nan diamond particles [3]. Reported that nanofluids can be used in several areas as heat-transfer nanofluids, surfactant, chemical and environmental nanofluids, bio, pharmaceutical and medical nanofluids and finally tribological nanofluids, there's the focus this paper.Nanofluids are a class of fluids which consist of a base fluid with nanosized particles $(1-100 \mathrm{~nm})$ suspended within them, can be a lubricant. These particles, generally a metal oxide [4], added to lubricant canimproveits performance. The preparation of nanofluids with controllable microstructure is oneof the key issues. It is well known that the properties of nanofluids strongly depend on the structure and shape of. In the field of metal nanoparticles, ferrofluids are of great technological importance and represent a new class of material consisting of magnetic nanoparticlesdispersed as colloids stabilized in a liquid carrier fluid and exhibiting magnetic properties like magnetorheology or superparamagnetism. The stability of these suspensions is achieved by coating the particles with surfactants consisting of long chain molecules, like oleic acid.

The ferrofluids can be used like nanofluids of aplication tribological, so there are many studies on automotive lubrication applications, surface modified nanoparticles stably dispersed in mineral oils are reported to be effective in reducing wear and enhancing load-carrying capacity. Results from a research project involving industry and university points to the use of nanoparticles in lubricants to enhance tribological properties such as load carry incapacity, wear resistance, and friction reduction between moving mechanical components. Such results are encouraging for improving heat transfer rates in automotive systems through the use of nanofluids.

\section{I.2 SYNTHESIS BY MICROWAVE}

The nanofluid microstructure can be varied and manipulated by adjusting synthesis parameters such as temperature, acidity, ultrasonic and microwave irradiation, types and concentrations of reactants and additives, and the order in which the additives are added to the solution.

One of high-speed techniques is by microwave synthesis, which has attracted a substantial amount of attention in the past few years. The main benefits of performing reactions under microwave irradiation conditions are the significant rate enhancements and the higher product yields that can frequently be observed. Not surprisingly, these features have recently also attracted interest from the drug discovery and medicinal chemistry communities and engineering, for which reaction speed is of great importance [5][6].

The combination of microwave heating technology and combinatorial chemistry and engineering applications, therefore, seems a logical consequence of the increased speed and effectiveness offered by using microwave irradiation instead of conventional heating methods. Although different hypotheses have been proposed to account for the observed rate enhancements under microwave irradiation, a generally accepted rationalization remains elusive [7]. Regardless of the origin/existence of a special microwave effect, it is extremely efficient and applicable to a broad range of practical syntheses [8].

Microwave heating is very convenient to use in oxide synthesis. The heating is instantaneous, very specific, and there is no contact required between the energy source and the reaction vessel. So, it can specify synthesis by microwave like a simple method and low cost to synthetize iron oxide nanoparticles for additive in lubricating, cause this method was chosen for this research.

\section{LITERATURE REVIEW}

\section{II.1 MATERIALS AND SYNTHESIS OF NANOPARTICLES}

Iron oxide nanoparticles were synthesized using the microwave technique with basic solution of Ferric chloride (3.38 g) with ammonium Hydroxide $(15 \mathrm{~mL})$. The solution was kept under magnetic stirring for 30 minutes, maintaining a pH of 10 . In Teflon vessel were added the solution and thermally treated using a microwave oven. The hydrothermal reaction was performed during 0.5 (sample A1) and 2.0 minutes (sample A2), at final temperature of $55{ }^{\circ} \mathrm{C}$ and $95{ }^{\circ} \mathrm{C}$, respectively. After synthesis, the powders were cooled, washed several times with water and ethanol until to reach neutral $\mathrm{pH}$ and heated.

\section{II..2 X-RAY DIFFRACTION (XRD)}

$\mathrm{X}$-ray diffractograms were recorded to determine the degree of crystallinity and phase of the iron oxides and as well as the size of the sample. It was used X-ray diffraction of Shimatzu Model 6000 diffractometer equipped with a $\mathrm{CuK}$ target (1.5408 $\AA$ ), voltage $40 \mathrm{kV}$ and $30 \mathrm{~mA}$ current. The scan was performed from 10 to 80 degrees, with the step of 0.02 degree and period of 3 seconds per step. All samples were characterized by technical in NUPPRAR (Processing Core Primary and Reuse Water and Produced and Reuse) UFRN.

For determined the growth of nanoparticles of samples, the average particle size for each sample was estimated using the Scherrer formula as Eq. (1): 
Ana Emília Diniz Silva Guedes et al./ITEGAM-JETIA Vol.02, No 05, pp.41-46. Março, 2016.

$\mathrm{D}=0.9 \lambda / \mathrm{B} \cos \theta$

Where $\mathrm{D}$ is average crystallite size, $\mathrm{k}$ is the $\mathrm{X}$-ray wavelength used, $\mathrm{b}$ is the angular line width of half maximum intensity and $\mathrm{h}$ is Bragg's angle in degrees. The instrument broadening has been estimated using well crystalline bulk Si.

\section{II.3 FORMATION OF ENERGY CRYSTALLITES}

In general, when nanoparticle are synthesized in solution, the nucleation, and subsequent growth is very fast and thus, it can be related with intensity energy and reaction time in microwave. It is possible to quantify the maximum energy required in formation and growth, through Eq. (2).

For the better explanation of the formation of crystallites and crystals, a comparison was made between the final diameter, the total time, energy and maximum temperature of the synthesis process, and finally it verify if there is a relationship between these parameters.

$$
E=P \cdot t(\mathrm{~J})
$$

Where:

E: Energy (Joule)

P: Microwave Power (Watts)

t: Time (Seconds)

\section{RESULTS AND DISCUSSION \\ III.1 PHYSICAL CHARACTERISTICS}

Both samples A1 and A2 showed the same color, brown tending to red, proving the formation of iron oxide. They should be hematite or magnetite Fig 1 .

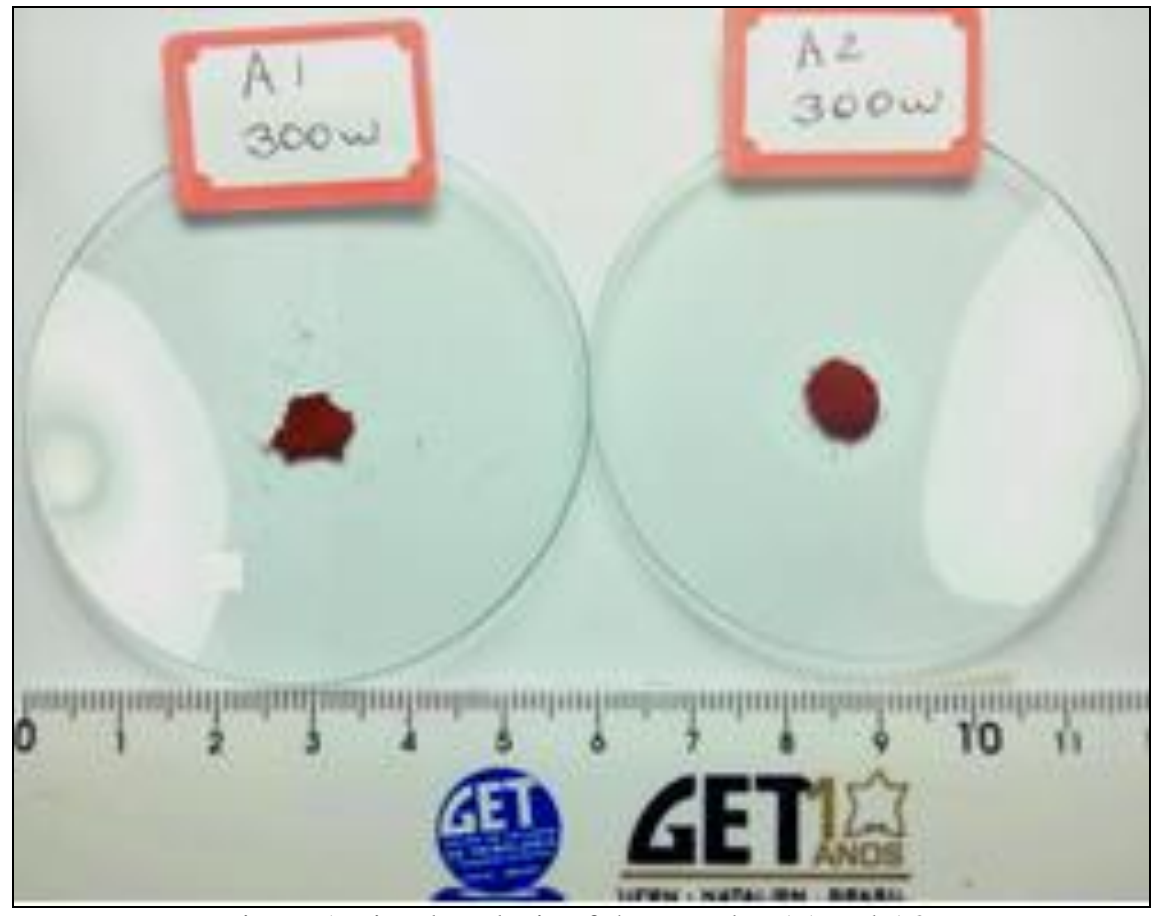

Figure 1.Visual analysis of the samples A1 and A2.

\section{III.2 X-RAY POWDER DIFFRACTION PATTERNS}

Figure 2shows X-ray powder diffraction patterns ofFe ${ }_{3} \mathrm{O}_{4}$ nanoparticles. Both Samples, A1, and A2, were irradiate with $300 \mathrm{~W}$ by microwave, but at different times. A1 was irradiated during 0.5 minutes and A2during 2.0 minutes,

From the patterns, hematite (PDF 33-664) and magnetite (PDF 19-629), compared with sample A1, it was found that there were a series of characteristic peaks at (220), (311), (511), and (400), as shown in Fig 3. The diameter values (sample A1) calculated from the XRD patterns were well indexed to the inverse cubic spinel phase of $\mathrm{Fe}_{3} \mathrm{O}_{4}$. The average crystallite size was obtained from Scherrer equation, and the result was approximately $4.0 \mathrm{~nm}$.
The patterns of sample A2 were similar to those of sample A1, magnetite and hematite are present, the average size was 7 $\mathrm{nm}$, the crystal size was bigger than A1. The difference between samples A1 and A2, beyond the Crystal size, is that the sample A2 showed peak (100), (110), (111), (200), (210), (211), (220), (221) e (310), this are characterized as crystal of $\mathrm{NH}_{4} \mathrm{Cl}$ (PDF73-365), where peak (110) with more intensity and HWFM with small value.The samples was prepared with the $\mathrm{NH}_{4} \mathrm{OH}$, but sample A2 had one more phase that A1, probably, because it was exposed to more time and more energy on microwave, developing this third phase, it's like a small amount of spinoff shown in Fig.3 .

Both samples nanoparticles (A1 and A2) have superparamagnetic properties because the size is less than $10 \mathrm{~nm}$ [9], there is a single domain theory. 


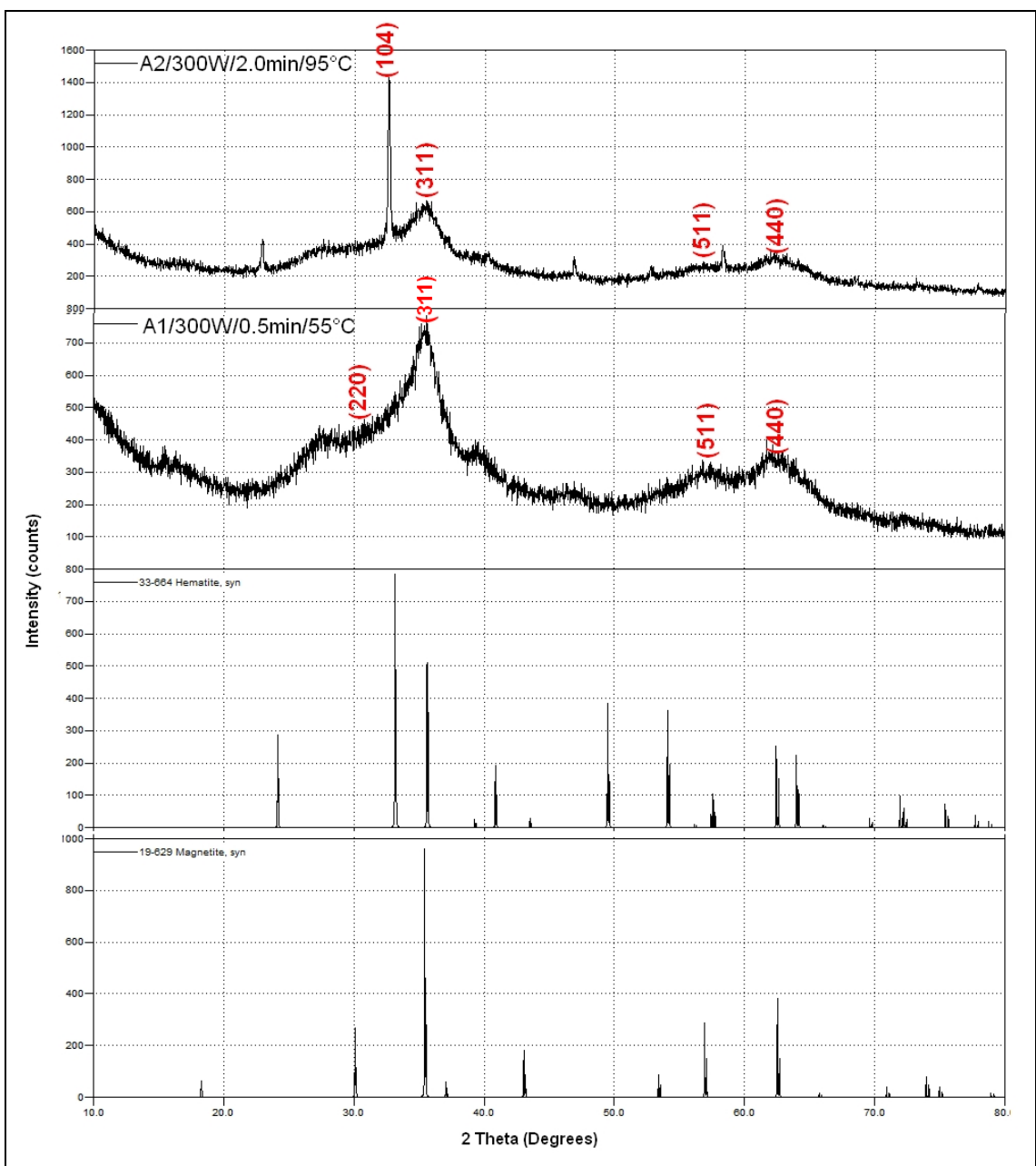

Figure 2- Comparison samples A1 and A2 with patterns.

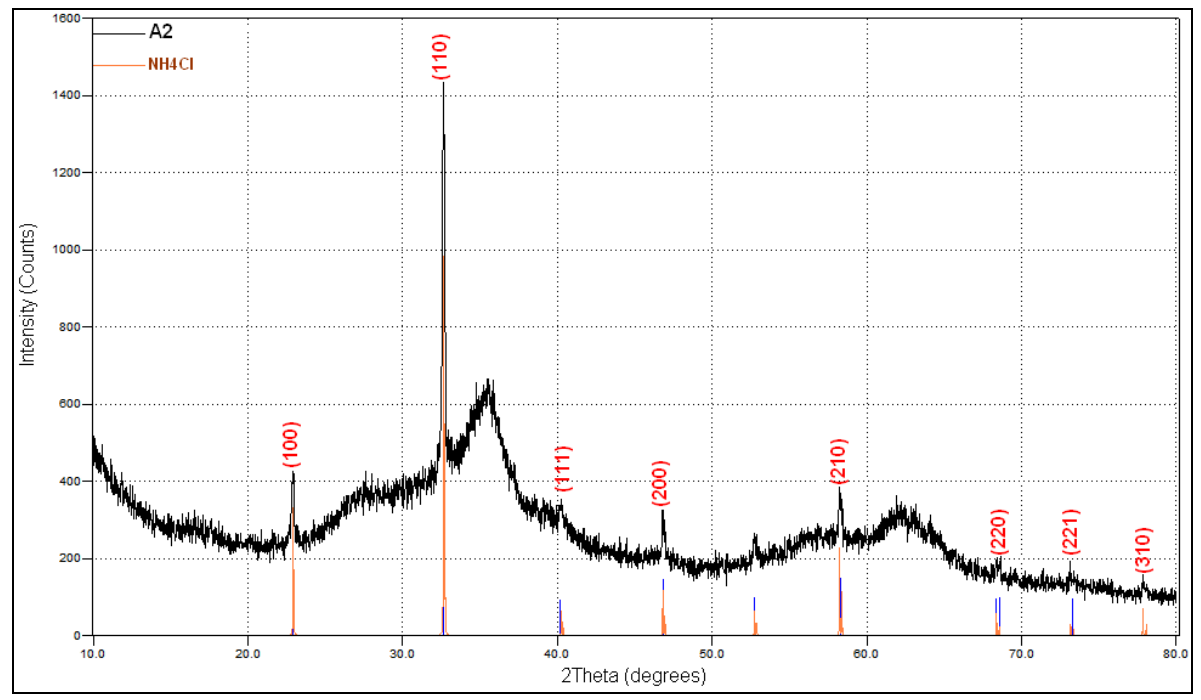

Figure 3. Comparison Sample A2 with pattern $\left(\mathrm{NH}_{4} \mathrm{Cl}\right)$.

\section{III.3 STUDY OF CRYSTALLITES FORMATION}

Table 1 lists the summary results of the two samples, include size in nanometer, the final temperature of synthesis, the same power in the microwave and total energy in the process. It is important a bounce about the concentration of reagents and $\mathrm{pH}$ because 
these parameters are fixed in both cases, A1 and A2.

Table 1-Results obtained from the two syntheses A1 and A2.

\begin{tabular}{|l|l|l|l|l|l|}
\hline Sample & Diameter $(\mathbf{n m})$ & $\begin{array}{l}\text { Temperature } \\
\left({ }^{\circ} \mathbf{C}\right)\end{array}$ & Power $(\mathbf{W})$ & Time $(\mathbf{s})$ & Energy $(\mathbf{J})$ \\
\hline A1 & 4.0 & 55 & 300 & 30 & 9,000 \\
\hline A2 & 7.0 & 95 & 300 & 120 & 36,000 \\
\hline
\end{tabular}

It is possible verify clearly, that with the increase of time and exposure to microwave energy, there is a linear rise in the average particle size synthesized, as can be appreciated by the graphs of Fig.4.

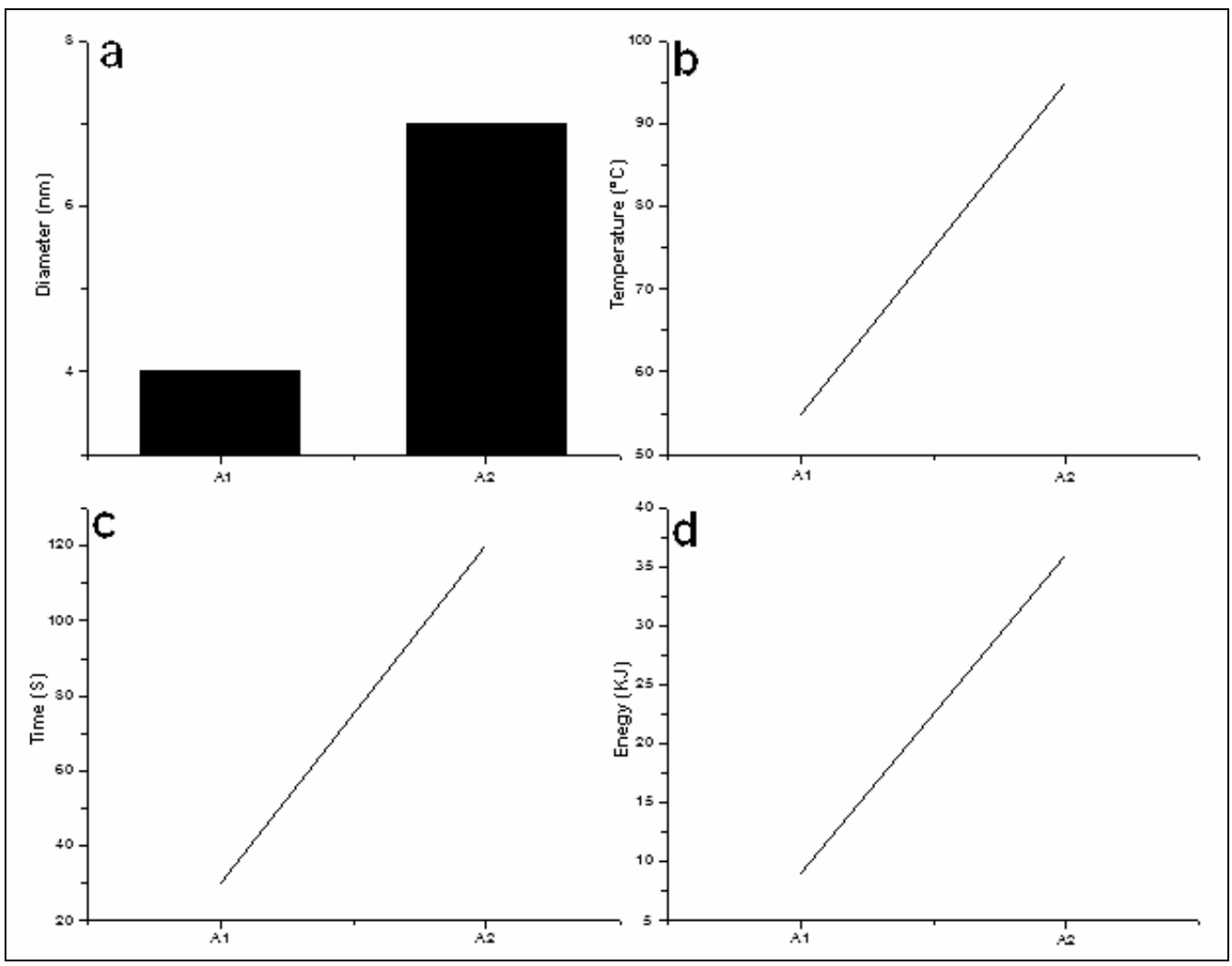

Figure 4. Comparison between crystal size and synthesis conditions (a- Size diameter; b- Temperature; c- Time; Energy).

The chemical synthesis of nanomaterials inevitably is related to the crystallization of solid phase from a solution, but, the nucleation and growth of crystals, It's directly proportional to increased time and hence temperature and total energy, but with the possibility of the emergence a unwanted residual phase, as the case of Sample A2.

As the formation of nuclei is over and the precursor concentration is not exceeded the supersaturation threshold, the growth of nanocrystals starts.At this stage, the additional reagents can only accumulate on the existing nuclei and the smaller nanocrystals grow faster than the larger ones, because the free energy of smaller nanocrystals is higher than that of larger ones, which is the so-called "focusing of the size distribution" stage [10].
Moreover, due to the fact that the growth of any nanocrystal is similar and homogeneous, the size distribution will be narrow if the reaction is arrested at size focusing stage. On the other hand, if it keeps the nanocrystal growth for a longer period, the depletion of active precursor will cause the concentration decreased and the relative smaller nanocrystals dissolved, as a result, the size distribution of nanocrystal will be broader.This hasbeen known as "Ostwald ripening". This is an explanation found for the emergence of the third phase in the sample A2.

\section{CONCLUSIONS}

Comparison of properties of the samples A1 and A2 allowed identifying different phase by XRD, the greater the reaction time increased the possibility of developing a residual phase. A1 had two phases and A2 three phases, with differents sizes. 
In general, the nanocrystal size is dependent on a set of reaction parameters such as temperature, time, and precursor concentration. The longer the reaction time and the higher the reaction temperature typically result in the formation of larger nanocrystals. The diameter of the samples were (A1: $4 \mathrm{~nm}$ and A2: $7 \mathrm{~nm}$ ).

\section{ACKNOWLEDGEMENTS}

The FAPEAM / Rh-Doctoral degree - Continuous Flow (Notice $n^{\circ} .004$ / 2013). The PRH-ANP 14 program of student UFRN. The PPGEM - Graduate Program in Mechanical Engineering from UFRN.

\section{REFERENCES}

[1] Duran, N; Mattoso, 1. H. C.; Morais, P., 2006. "Nanotecnologia: introdução, preparação e caracterização de nanomateriais e exemplos de aplicação". Artliber: São Carlos.

[2] Gomes, J. A.; Azevedo, G. M.; depeyrot, J., 2011. “ZnFe2O4 nanoparticles for ferrofluids: A combined XANES and XRD study. "Journal of Magnetism and Magnetic Materials, v. 323, n. 10, p. 1203-1206.

[3] Botha SS. 2007. Synthesis and characterization of nanofluids for cooling applications. $\mathrm{PhD}$ thesis. University of the Western Cape.

[4] Choi SUS. In: Singer DA, Wang HP, editors.1995. "Development and application of non-Newtonian flows", vol. FED 231. New York: ASME; p. 99-105.

[5] Larhed M, Hallberg A.2001. "Microwave-assisted highspeed chemistry: a new technique in drug discovery." Drug Discov Today, 6:406-416. A review dedicated to the application of high-speed microwave synthesis to medicinal chemistry.

[6] Krstenansky JL, Cotterill I. 2000. "Recent advances in microwave-assisted organic synthesis". CurrOpin Drug DiscovDev 4:454-461.

[7] Perreux L, Loupy A.2001. "A tentative rationalization of microwave effects in organic synthesis according to the reaction medium, and mechanistic considerations". Tetrahedron, 57:9199-9223.

[8] Lidström P, Tierney J, Wathey B, Westman J.2000. "Microwave assisted organic synthesis-a review". Tetrahedron. 57:9225-9283.

[9] Lu, A-H., Salabas, E.L., Schuth, F..2007. "Magnetic nanoparticles: synthesis, protection, functionalization and application". AngewandteChemie International Edition, vol.46, $\mathrm{N}^{\circ} 8$, p. 1222-1244.

[10] Peng, X. J.2003. "Mechanisms for the Shape-Control and Shape-Evolution of Colloidal Semiconductor
Nanocrystals" Advanced Material. 124, 3343. Pages 459-463. 